\title{
Synthesis of Chromen[4,3-b]pyrrolidines by Intramolecular 1,3- Dipolar Cycloadditions of Azomethine Ylides: Experimental and Computational Assessment of the Origin of Stereocontrol
}

\author{
Paulo R. R. Costa, ${ }^{[a]}$ José M. Sansano, ${ }^{[\mathrm{b}]}$ Unai Cossío, ${ }^{[\mathrm{c}]}$ Julio C. F. Barcellos, ${ }^{[\mathrm{a}]}$ Ayres G. \\ Dias, ${ }^{\left[{ }^{[d]}\right]}$ Carmen Nájera, ${ }^{[b]}$ Ana Arrieta, ${ }^{[c]}$ Abel de Cózar, ${ }^{[c, e]}$ Fernando P. Cossío ${ }^{\#[c]}$
}

Dedicated to Dr. Jean-Paul Picard, in memoriam

\begin{abstract}
Azomethine ylides, generated from imines derived $O$ cynnamyl or O-crotonyl salicylaldeyde and $\alpha$-amino acids, undergo intramolecular 1,3-dipolar cycloaddition, leading to chromene-[4,3b]-pyrrolidines. Two reaction conditions are used: a) microwave irradiation $(200 \mathrm{~W})$ assisted heating $\left(185^{\circ} \mathrm{C}\right)$ of a neat mixture of reagents, and b) conventional heating $\left(170^{\circ} \mathrm{C}\right)$ in PEG-400 as solvent. In both cases mixture of two epimers at the $\alpha$-position of the nitrogenatom in the pyrrolidine nucleus was formed through the less energetic endo-approach (B/C ring fusion). In many cases, the formation of the stereoisomer bearing a transarrangement into the $\mathrm{B} / \mathrm{C}$ ring fusion in high proportions. A comprehensive computational and kinetic simulation studies are detailed. The analysis of the stability of transient 1,3-dipoles, followed by the assessment of intramolecular pathways and kinetic are carefully performed.
\end{abstract}

\section{Introduction}

The chromene-[4,3-b]-pyrrolidine moiety is present in many compounds exhibiting remarkable physiological properties (Figure 1). This structural motif ${ }^{[1,2]}$ is present in compound $\mathbf{1}^{[3]}$ and constrained analogs of methoctramine $2,^{[4]}$ which are antagonist of muscarinic acetyl choline receptors (mAChR). The diazo-derivative $\mathbf{3}^{[5]}$ is a key precursor in the preparation of new amino azachromenes displaying photochromic properties (Figure 1).The chromene moiety is also present in a new class

[a] Laboratório de Química Biorgânica, Núcleo de Pesquisas de Produtos Naturais, Centro de Ciencias da Saúde Universidade Federal do Rio de Janeiro

Cidade Universitária, 21941-590, Rio de Janeiro, Brazil

[b] Departamento de Química Orgánica, Instituto de Síntesis Orgánica (ISO), and Centro de Innovación en Química Avanzada (ORFEO-CINQA),

Universidad de Alicante,

Apdo. 99, E-03080-Alicante, Spain

E-mail:imsansano@ua.es

[c] Departmento de Química Orgánica I, Facultad de Química, and Centro de Innovación en Química Avanzada (ORFEO CINQA), Universidad del País Vasco/Euskal Herriko Unibertsitatea (UPV/EHU), and Donostia International Physics Center (DIPC)

Manuel Lardizábal 3, E-20018 San Sebastián, Spain. E-mail: fp.cossio@ehu.es

[d] Instituto de Química Universidade do Estado do Rio de Janeiro UERJ. Rua São Francisco Xavier 524, PHLC, $3^{\circ}$ andar 20550

900. Rio de Janeiro-RJ, Brazil.

E-mail: ayres.dias@gmail.com

[e] IKERBASQUE, Basque Foundation for Science, E-48011 Bilbao, Spain. of modified isoflavonoids LQB-226 (4) (Figure 1), which present antineoplastic and antiparasitary properties. ${ }^{[6]}$ Encouraged by these properties we proposed the synthesis of related compounds $\mathbf{5}$ in order to study their bifunctional biological activity. ${ }^{[7]}$
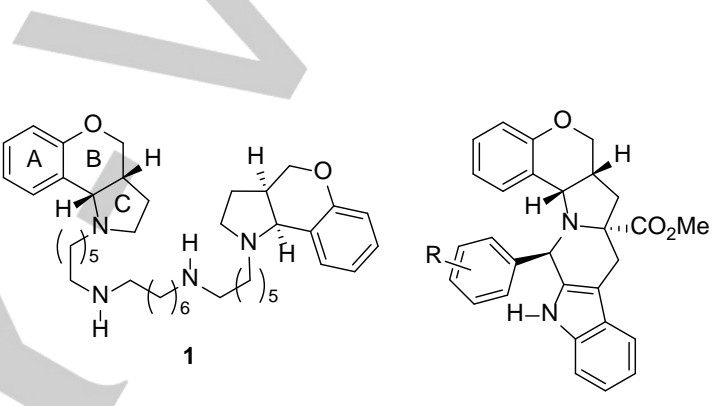

2

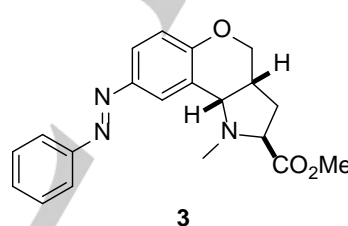

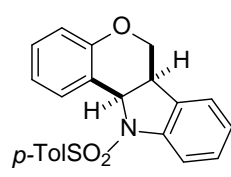

4

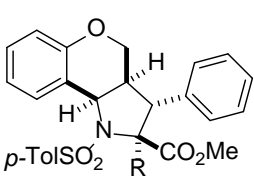

5
Figure 1. Selected bioactive compounds bearing the chromene-[4,3b]-pyrrolidine moiety.

The most accessible routes to achieve these fused chromenepyrrolidine skeleton consists on the employment of an intramolecular 1,3-dipolar cycloaddition (1,3-DC) between azomethine ylides and alkenes as key step. ${ }^{[8]}$ The 1,3-dipolar reaction between azomethine ylides and alkenes lead to the efficient regio- and stereocontrolled chemical synthesis of pyrrolidines, ${ }^{[9,10]}$ whose relevance in biological chemistry ${ }^{[11]}$ and materials science ${ }^{[12]}$ is very well known. The synthesis of these particular polycyclic compounds (with a core pyrrolidine ring ${ }^{[13]}$ has been achieved through this intramolecular reaction onto imines $\mathbf{8}^{[14,15,16,17]}$ or in situ generated iminium salts $\mathbf{1 0}$, which were prepared by reaction of $O$-allylated salicylaldehydes 6 with amino esters $\mathbf{7}$ or $\mathrm{N}$-alkyl amino esters $\mathbf{9}$, respectively (Scheme 1). ${ }^{[18,1920]}$ Imines $8\left(R^{1}=P h\right)$ do not react under thermal conditions, so the use of the more reactive iminium cations type 10 is recommended in this case. ${ }^{[21,22,23,24,25,26]}$ 


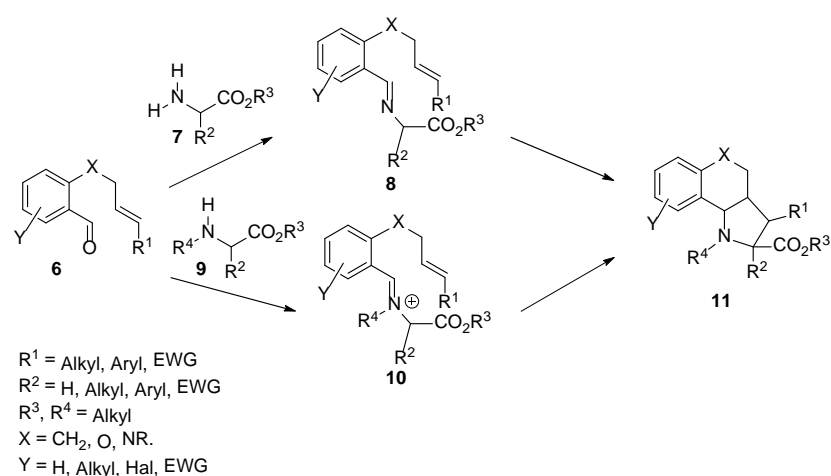

Scheme 1. Synthetic strategies for the synthesis of compounds $\mathbf{1 1}$ using either imines $\mathbf{8}$ or iminium salts $\mathbf{1 0}$.

Considering both strategies, there are two difficulties to overcome. In the first route, the resulting imine $\mathbf{8}$ is, in some cases, unstable, and in the second one, $\mathrm{N}$-alkyl amino esters $\mathbf{9}$ have to be prepared. In order to increase the efficiency of the last process to finally synthesize compounds $\mathbf{5}$, we decided to investigate the two-component [3+2] cycloaddition where the imines were prepared in situ from 6 and 7 (Figure 2). The effect of the microwaves in the overall reaction course as well as the identification of all detected stereoisomers from crude reaction mixtures will be considered. In addition, the preparation of $\mathrm{N}-\mathrm{H}$ derivatives makes the synthesis more attractive, allowing additional substitution at the nitrogen atom. The computational study of the simplest skeleton will be very helpful to determine a reasonable justification to the reaction of the azomethine ylide onto an electronically rich olefin, which is very difficult to achieve in an intermolecular version.

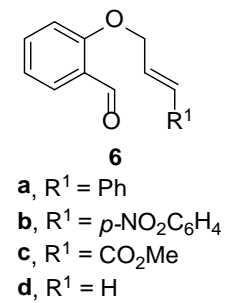

$$
\begin{aligned}
& \mathrm{R}^{3} \mathrm{O}_{2} \mathrm{C}_{\mathrm{R}^{2}}^{\mathrm{NH}_{2} \cdot \mathrm{HCl}} \\
& 7 \\
& \text { a, } \mathrm{R}^{2}=\mathrm{CO}_{2} \mathrm{Et}, \mathrm{R}^{3}=\mathrm{Et} \\
& \text { b, } \mathrm{R}^{2}=\mathrm{H}, \mathrm{R}^{3}=\mathrm{Me} \\
& \text { c, } \mathrm{R}^{2}=\mathrm{Me}, \mathrm{R}^{3}=\mathrm{Me} \\
& \text { d, } \mathrm{R}^{2}=\mathrm{Bn}, \mathrm{R}^{3}=\mathrm{Me}
\end{aligned}
$$

Figure 2. Salicylaldehydes and amino acid derivatives used in this study.

\section{Results and Discussion}

\section{Synthesis of Compounds 5 by Intramolecular 1,3-DC}

Compounds $\mathbf{6 a}$, and $\mathbf{6 b}$ were prepared by $O$-alkylation of salicylaldehyde 12 with cynnamyl bromides 13 according to standard procedures (Scheme 2), in good yields (70 and 73\%, respectively). The $p$-nitrocinnamyl bromide $13 \mathbf{b}$ was prepared from the corresponding alcohol in $73 \%$ global yield. Several attempts to prepare $p$-methoxycinnamyl derivative $6\left(\mathrm{R}^{1}=\mathrm{OMe}\right)$ were unsuccessful.

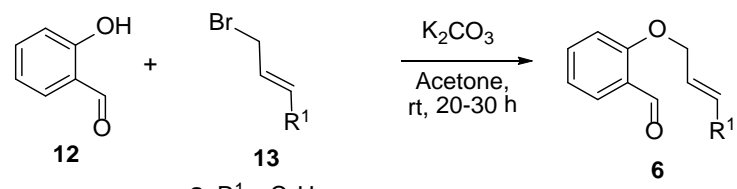

$$
\text { a, } \mathrm{R}^{1}=\mathrm{C}_{6} \mathrm{H}_{5}
$$$$
\text { b, } \mathrm{R}^{1}=4-\mathrm{NO}_{2} \mathrm{C}_{6} \mathrm{H}_{5} \quad \text { a, } \mathrm{R}^{1}=\mathrm{Ph}(70 \%)
$$$$
\text { c, } \mathrm{CO}_{2} \mathrm{Me} \quad \text { b, } \mathrm{R}^{1}=p-\mathrm{NO}_{2} \mathrm{C}_{6} \mathrm{H}_{4}(73 \%)
$$$$
\text { d, } \mathrm{R}^{1}=\mathrm{H}
$$$$
\text { c, } \mathrm{R}^{1}=\mathrm{CO}_{2} \mathrm{Me}(98 \%)
$$$$
\text { d, } \mathrm{R}^{1}=\mathrm{H}(95 \%)
$$

Scheme 2. Synthesis of aldehydes 6 .

With compounds $\mathbf{6}$ in hand, we decided to try the two component reactions in the presence of the corresponding amino acid alkyl ester hydrochloride 7, that means imine formation and cyclization in one pot process, either under microwave assisted heating or using conventional heating. After the optimization process, the best reaction conditions consisted in: Method $\mathrm{A}$ : neat, $185^{\circ} \mathrm{C}, 200 \mathrm{~W}$ of microwave irradiation and Method B: polyethyleneglycol (PEG)-400 at $170^{\circ} \mathrm{C}$.

The condensation of diethyl aminomalonate hydrochloride 7a with aldehyde $\mathbf{6 a}$ followed by the intramolecular 1,3-DC was successfully performed following Method A (Table 1, entry 1 ). In this case, the Method B afforded lower yield of a very complex reaction mixture. To the best of our knowledge, this is the first time that freshly generated imino ester 8aa gives a intramolecular 1,3-DC with $\mathrm{R}^{1}=\mathrm{Ph}$. Glycine derivative hydrochloride $\mathbf{7 b}$ was also tested, Method $\mathrm{A}$ being the most appropriate giving a $45 \%$ yield of a mixture of three diastereoisomers 14ab, 15ab and 16ab (Table 1, entries 2 and 3). The employment of natural $\alpha$-substituted amino ester hydrochlorides also required Method $A$ to achieve better chemical yields and higher diastereoselectivities for products 14ac and 14ad (Table 1, entries 4-7). The influence of the electronic nature of the group in the allyl ether precursor 6 was next surveyed. For electron-deficient arenes $\left(\mathrm{R}^{1}=p-\mathrm{NO}_{2} \mathrm{C}_{6} \mathrm{H}_{4}\right)$ the reaction worked in short reaction times giving adducts $14 \mathrm{bb}$ 14bd as major diastereoisomers (Table 1, entries 8-10). In the series of electron-withdrawing groups such as $\mathrm{R}^{1}=\mathrm{CO}_{2} \mathrm{Me}$ both methods resulted to be satisfactory in terms of the overall yield (Table 1, entries 11-17). The diastereoselectivity was also noticeable always in favor of compound 14 when the glycinederived amino ester hydrochloride $\mathbf{7 b}$ was employed (Table 1 , entries 12 and 13). However, diethyl aminomalonate furnished a 1:1 mixture of epimers 14ca and $16 \mathbf{c a}$ (Table 1, entry 11).The reaction of $\alpha$-alkyl substituted amino esters $\mathbf{7 c}$ and $\mathbf{7 d}$ was much more stereoselective and only small amounts of trans-fused isomers were observed in the crude product. Thus, when alanine methyl ester hydrochloride 7c was allowed to react with 6c. Method B afforded the highest chemical yield and the best 14cc:16cc diastereomeric ratio (80:20) (Table 1, entries 14 and 15). In contrast, Method A was the most appropriate in the reaction involving $\mathbf{6 c}$ and phenylalanine methyl ester hydrochloride $\mathbf{7 d}$. Here, polycycle $\mathbf{1 4 c d}$ was the major stereoisomer isolated (70:30 dr) in 68\% combined yield (Table 1, entry 17). Unfortunately, the reaction performed with the allylic system $\mathbf{6 d}$, following both method conditions, completely failed. 


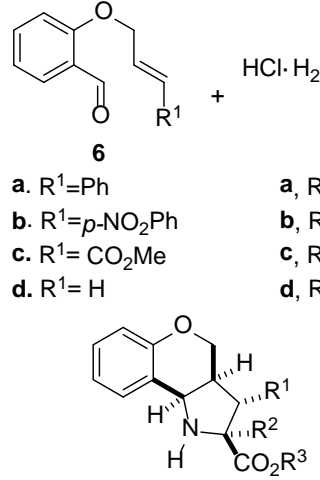

14
15

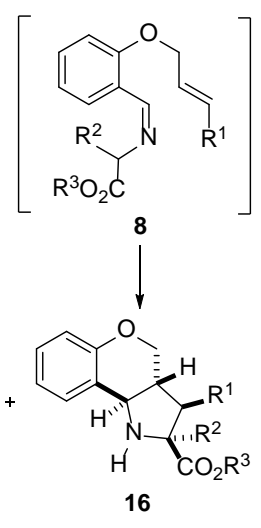

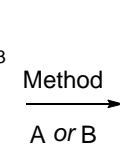

$\mathrm{R}^{2}=\mathrm{CO}_{2} \mathrm{Et}$

b, $\mathrm{R}^{2}=\mathrm{H}$

c, $R^{2}=M e$

$\mathrm{R}^{2}=\mathrm{Bn}$

\begin{tabular}{|c|c|c|c|c|c|c|c|}
\hline En. & $\mathrm{R}^{1}$ & $\mathrm{R}^{2}$ & $\mathrm{R}^{3}$ & Method & $\begin{array}{l}\text { Time } \\
(\min )\end{array}$ & $(14: 15: 16)^{[b]}$ & $\begin{array}{l}\text { Yield } \\
(\%)^{[c]}\end{array}$ \\
\hline 1 & $\mathrm{Ph}$ & $\mathrm{CO}_{2} \mathrm{Et}$ & Et & $A$ & 60 & aa $(90: 0: 10)$ & 83 \\
\hline 2 & $\mathrm{Ph}$ & $\mathrm{H}$ & $\mathrm{Me}$ & $A$ & 20 & ab $(65: 24: 11)$ & 45 \\
\hline 3 & $\mathrm{Ph}$ & $\mathrm{H}$ & $\mathrm{Me}$ & B & 90 & ab (50:30:20) & 15 \\
\hline 4 & $\mathrm{Ph}$ & $\mathrm{Me}$ & $\mathrm{Me}$ & $A$ & 20 & ac $(83: 0: 17)$ & 77 \\
\hline 5 & $\mathrm{Ph}$ & $\mathrm{Me}$ & $\mathrm{Me}$ & $B$ & 60 & ac $(70: 0: 30)$ & 51 \\
\hline 6 & $\mathrm{Ph}$ & $\mathrm{Bn}$ & $\mathrm{Me}$ & $A$ & 120 & ad (68:22:10) & 79 \\
\hline 7 & $\mathrm{Ph}$ & $\mathrm{Bn}$ & $\mathrm{Me}$ & B & 150 & ad $(64: 36: 0)$ & 22 \\
\hline 8 & $\begin{array}{c}p- \\
\mathrm{NO}_{2} \mathrm{Ph}\end{array}$ & $\mathrm{H}$ & $\mathrm{Me}$ & $A$ & 20 & bb $(55: 26: 19)$ & 96 \\
\hline 9 & $\begin{array}{c}p- \\
\mathrm{NO}_{2} \mathrm{Ph}\end{array}$ & $\mathrm{Me}$ & $\mathrm{Me}$ & $A$ & 20 & bc (80:0:20) & 74 \\
\hline 10 & $\begin{array}{c}p- \\
\mathrm{NO}_{2} \mathrm{Ph}\end{array}$ & $\mathrm{Bn}$ & $\mathrm{Me}$ & $A$ & 120 & bd $(54: 38: 8)$ & 92 \\
\hline 11 & $\mathrm{CO}_{2} \mathrm{Me}$ & $\mathrm{CO}_{2} \mathrm{Et}$ & Et & $A$ & 60 & ca $(50: 0: 50)$ & 50 \\
\hline 12 & $\mathrm{CO}_{2} \mathrm{Me}$ & $\mathrm{H}$ & $\mathrm{Me}$ & $A$ & 20 & cb $(60: 0: 40)$ & 50 \\
\hline 13 & $\mathrm{CO}_{2} \mathrm{Me}$ & $\mathrm{H}$ & $\mathrm{Me}$ & $B$ & 20 & cb $(60: 0: 40)$ & 45 \\
\hline 14 & $\mathrm{CO}_{2} \mathrm{Me}$ & $\mathrm{Me}$ & Me & $A$ & 20 & cc $(60: 0: 40)$ & 50 \\
\hline 15 & $\mathrm{CO}_{2} \mathrm{Me}$ & $\mathrm{Me}$ & $\mathrm{Me}$ & $B$ & 20 & cc $(80: 0: 20)$ & 64 \\
\hline 16 & $\mathrm{CO}_{2} \mathrm{Me}$ & $\mathrm{Bn}$ & $\mathrm{Me}$ & $A$ & 120 & cd $(70: 0: 30)$ & 68 \\
\hline 17 & $\mathrm{CO}_{2} \mathrm{Me}$ & $\mathrm{Bn}$ & $\mathrm{Me}$ & B & 60 & cd $(66: 0: 34)$ & 45 \\
\hline
\end{tabular}

${ }^{\text {aa }}$ Method A : MW (200W), $185^{\circ} \mathrm{C}$. Method B: PEG-400, $170{ }^{\circ} \mathrm{C}$. [b] Determined by CG-MS and ${ }^{1} \mathrm{H}$ NMR for the crude product. The same ratio of products was obtained after purification. ${ }^{[\mathrm{c}]}$ Yield of the mixture obtained after flash chromatography.

The presence of mixtures of cycloadducts $\mathbf{1 4}$ and $\mathbf{1 5}$ in different proportions is in accordance with the previous publications. ${ }^{[14-20]}$ However, the isolation of a third stereoisomer 16 in high percentages was unexpected. For the analysis of the relative configuration single crystal X-ray diffraction and different NMR experiments were combined. The absence of a third chiral center (at the a-position) simplified the analysis of the stereochemical outcome of the chromene-pyrrolidine fusion. Based on the NMR analysis of the major endo-adducts 14 (coupling constants and NOESY studies) it was not possible to determine unambiguously the relative configuration. Fortunately, the relative configuration of structure $14 a c$ was established by $X$-ray diffraction analysis ${ }^{[27]}$ (see, supporting information). An identical protocol for separated/isolated compounds $15 \mathrm{ab}$ and $16 \mathrm{bb}, \mathbf{b c}, \mathbf{c b}$ and $\mathbf{c d}$ was followed, but it was not possible to obtain neither appropriate crystals nor consistent X-ray diffraction patterns.

The cis-configuration could be assigned to the ring junction of all the cycloadducts by comparison of the coupling constant of compounds 14ac (unequivocally characterized by crystal X-ray diffraction analysis)and 14ad. The stereochemistry also could be analyzed by 2D nuclear Overhauser effect spectroscopy (NOESY) of 14ac and 14ad. These NOESY contacts were found to be compatible with the corresponding MM3-minimized structures, in which Monte Carlo simulations in $\mathrm{CHCl}_{3}$ showed quite rigid $A B$ scaffolds with conformationally flexible pyrrolidinyl, methoxycarbonyl, methyl, and benzyl groups (Figure 3).
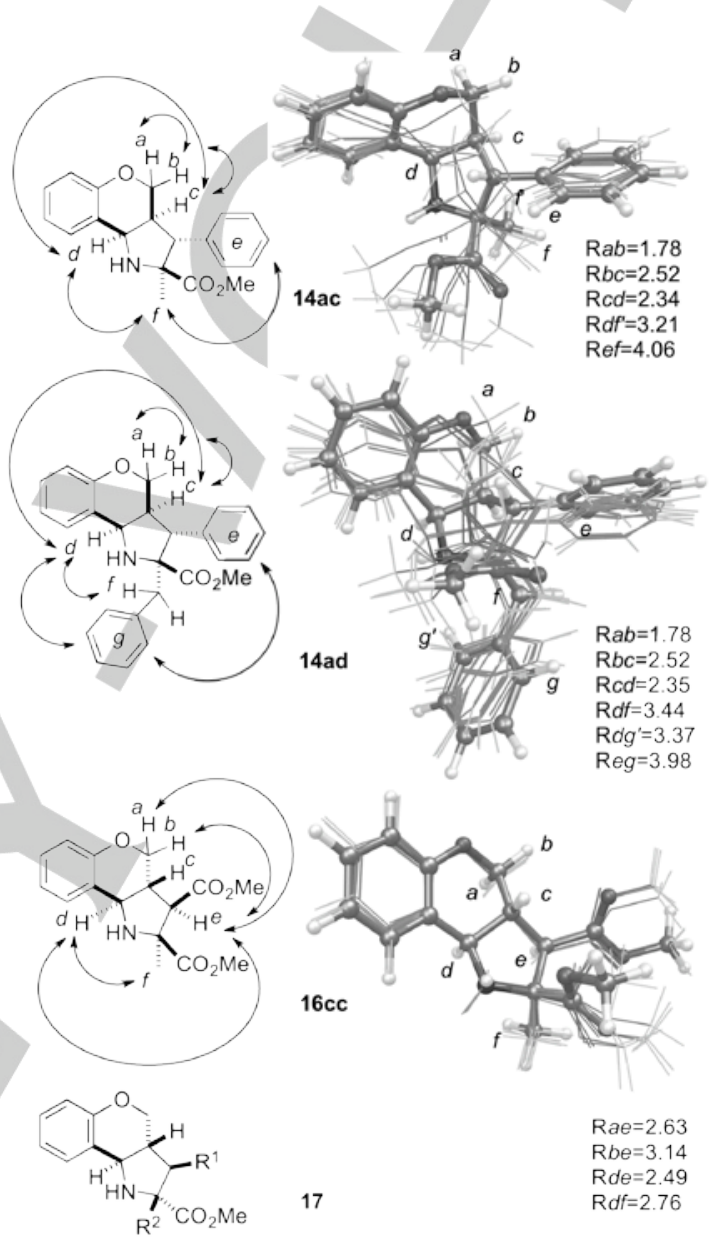

Figure 3. $\mathrm{MM} 3\left(\mathrm{CHCl}_{3}\right)$ minimized structures, NOESY contacts observed in compounds 14ac, 14ad and 16cc, and relative configuration of racemic compounds 17 . Distances are given in $\AA$. Ball \& stick structures correspond to the minimum energy conformers after Monte Carlo simulations. The remaining ten structures for compounds 14ac, 14ad and 16cc correspond to conformers within 3-2 $\mathrm{kcal} \mathrm{mol}^{-1}$ with respect to the respective conformational minima.

The trans-arrangement in molecules $\mathbf{1 6}$ was deduced from the analysis of coupling constants and all the information supplied by NOESY experiments (see supporting information) and by comparison with the coupling constants reported in the literature. ${ }^{[15]}$ Our $\mathrm{MM}_{3}\left(\mathrm{CHCl}_{3}\right)$ Monte Carlo simulations show that the tricyclic scaffold in $\mathbf{1 6 c c}$ is more rigid than those computed for diastereomers 16 (see Figure 3). On the other hand, the presence of stereoisomer $\mathbf{1 7}$ can be discarded.

Next, the transformation of major compounds $\mathbf{1 4}$ in the corresponding bioactive tosylamides $\mathbf{5}$ was carried out following 
a standard procedure (Scheme 3). In addition, the relative configuration of $\mathbf{5 a b}$ derived from $\mathbf{1 4 a b}$ was confirmed by X-ray diffraction analysis (see supporting information). ${ }^{[28]}$<smiles>[R]C1NC2c3ccccc3OCC2C1c1ccccc1</smiles>

14

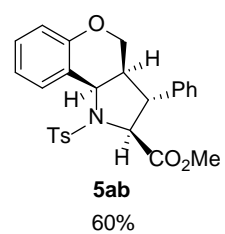

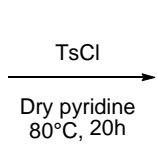

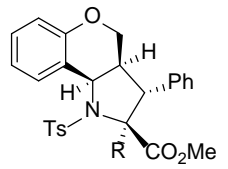

5
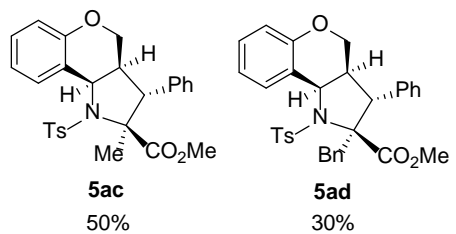

Scheme 3. Preparation of $\mathrm{N}$-tosyl derivatives 5ab-ad.

\section{Computational studies}

General considerations. The mechanism of 1,3-dipolar cycloadditions has been studied in detail ${ }^{[2]}$ and it has been concluded that, depending on the substitution pattern, the [3+2]thermal cycloaddition between $\mathrm{NH}$ - and $\mathrm{N}$-metallated azomethine ylides can take place via a concerted $[\pi 4 s+\pi 2 s]$ pathways $^{[30]}$ or through a stepwise mechanism involving zwitterionic intermediates. [ ${ }^{31}$ ] However, the intramolecular version of the reaction between azomethine ylides and alkenes have been less studied. ${ }^{[32]}$ In particular, to the best of our knowledge, the concerted or stepwise nature of the mechanism of this particular transformation has not been assessed. One important feature of intramolecular $1,3-D C$ is the possibility of generating fused or bridged regioisomers (Scheme 4). In general, the restricted conformational freedom imposed by the spacer connecting the dipole and the dipolarophile moieties results in high regiocontrol, except when the spacer is large enough. ${ }^{[33]}$ If the spacer (denoted as $\Sigma$ in Scheme 4) connects the alkene and one of the carbon atoms of the azomethine ylide (I), both fused and bridged cycloadducts (IIF and IIB, respectively) can be formed. In contrast, when the spacer links the olefinic moiety with the central $\mathrm{N}$-atom of the dipole, only bridged [3+2] cycloadducts can be formed (Compounds IVB and IVB'). Here, we will focus on the origins of the stereocontrol in several I $\rightarrow$ IIF cycloadditions.

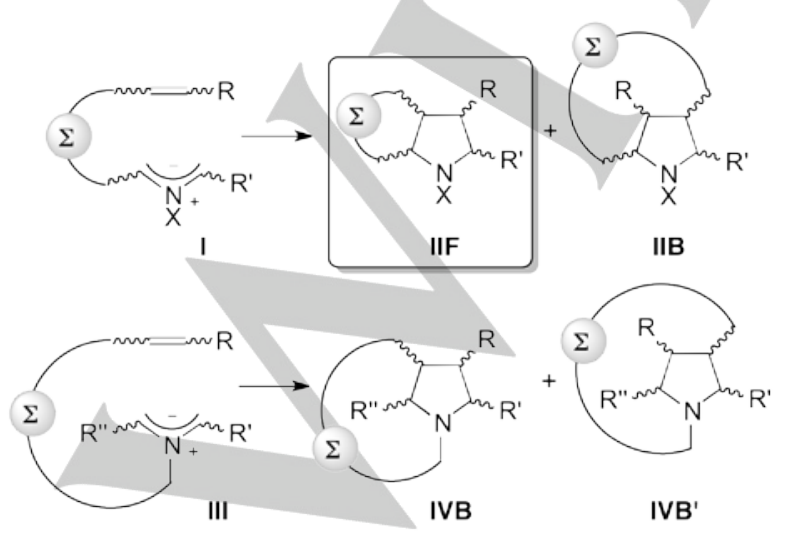

Scheme 4. Fused (F) and bridged (B) regioisomers in intramolecular $[3+2]$ cycloadditions between azomethine ylides and alkenes The specific intramolecular process addressed in this work is highlighted.

The stereochemistry of these reactions is in principle complex since two diastereoisomers and up to four chiral centers can be formed in one preparative step, thus giving rise to a maximum of $2 \times V R_{2}{ }^{4}=32$ possible isomeric cycloadducts, which can be reduced to 16 racemic diastereoisomers. As far as the possible configurations of azomethine ylides I are concerned, at least four possible conformers can be envisaged. These conformers are denoted as IW, IS, IS' and IU depending upon the relative positions of the substituents at the terminal carbon atoms of the 1,3-dipole (Scheme 5). In general, $\mathrm{X}$ can be $\mathrm{H}$, alkyl, or a metal with different ligands, and $B$ is an electron-withdrawing group such as methoxycarbonyl.

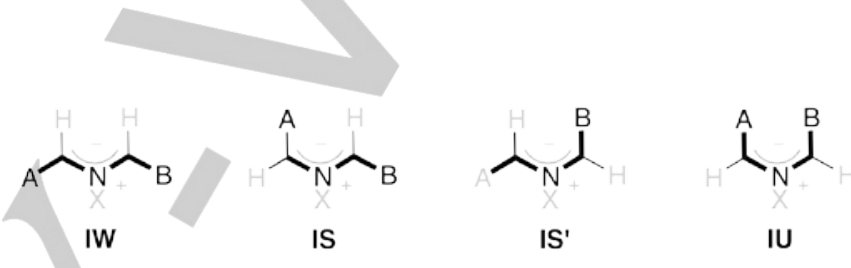

Scheme 5. Possible geometries of azomethine ylides I.

Reactive intermediates I can in turn react intramolecularly with an alkene to yield, for a given regioisomer, two possible racemic pairs of diastereoisomers. For instance, in Scheme 6 we have depicted the four possible pyrrolidine racemic cycloadducts corresponding to the [3+2] cycloaddition between $\mathrm{NH}$ azomethines of $\mathbf{W}$ and $\mathbf{S}^{\prime}$ configuration $\left(X=\mathrm{H}, \mathrm{B}=\mathrm{CO}_{2} \mathrm{Me}\right)$ and a trans-alkene. We denote endo-cycloadducts as those in which the $\mathrm{R}$ and $\mathrm{A}$ substituents are cis to each other, the alternative exo-pyrrolidines IIF possessing these substituents in a trans relative stereochemistry.

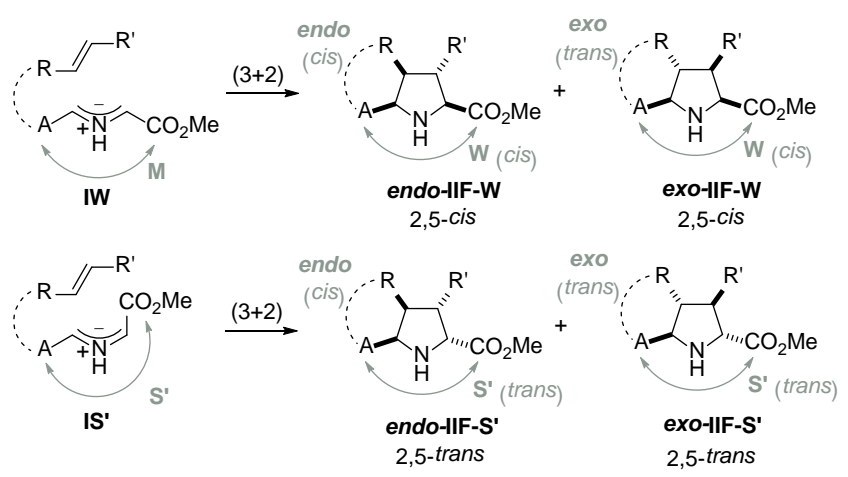

Scheme 6. Pyrrolidine cycloadducts associated with the [3+2] cycloaddition between $(E)$-olefins and azomethine ylides $\mathbf{I W}^{\mathbf{a}}$ and $1 \mathbf{S}^{\text {,a }}$. ${ }^{\mathrm{a}}$ Only one enantiomer and regioisomer is represented in each case

Since in the considered reaction the initial reactants are in situ generated imines $\mathbf{8 b}$ (Scheme 1), the actual steps leading to 
cycloadducts 14ab-17ab involve (i) generation of the 1,3-dipoles, and (ii) intramolecular $(3+2)$ cycloadditions. Our computational results on both steps will be presented and discussed in the following sub-sections.

Generation of 1,3-Dipoles. We first analyzed computationally the generation of azomethine ylides $\mathbf{8}_{\mathbf{w}} \mathbf{a b}$ and $\mathbf{8}_{\mathbf{s}}$, $\mathbf{a b}$. This process can be formally considered as a 1,2-prototropy, in which an acidic proton on $\alpha$-position of the methoxycarbonyl group migrates to the iminic nitrogen (Scheme 7). In a previous work, ${ }^{[31 \mathrm{c}]}$ we have demonstrated that the only possible energetically feasible pathway to generate azomethine ylides $\mathbf{W}$ consists of an enolization of the initial imino ester followed by a pseudopericyclic [1,5]-prototropy (vide infra). On the other hand, azomethine ylides $\mathbf{S}$ ' can be generated by cis-trans isomerization of the former azomethine ylide. In order to reproduce the harsh conditions required experimentally (namely high temperatures and/or microwave irradiation, vide supra) both $298 \mathrm{~K}$ and $460 \mathrm{~K}$ temperatures were considered in our study. The obtained reaction profiles and the main geometric features of the computed transition structures associated with the formation of ylides $\mathbf{8}_{\mathrm{w}} \mathbf{a b}$ and $\mathbf{8}_{\mathrm{s}}$, ab are gathered in Scheme 7 and Figure 4, respectively.

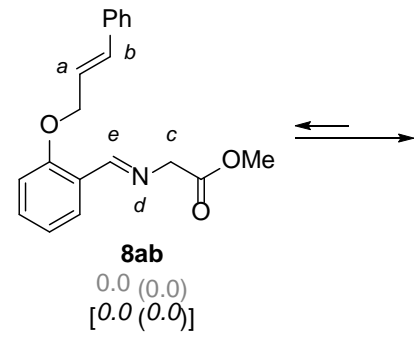

$$
\text { [+11.8(+13.0)] }
$$

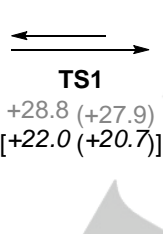

shift to yield azomethine ylide $\mathbf{8}_{\mathbf{w}} \mathbf{b}$. The activation barrier associated to this process is ca. $8 \mathrm{kcal} \mathrm{mol}^{-1}$ at both temperatures. This low value and the planar geometry of the system (See Figure 4) are compatible with the pseudoperyciclic nature of TSO.[ $\left.{ }^{34}\right]$ Moreover, formation of $\mathbf{8}_{\mathrm{Wa}} \mathbf{b}$ is thermodynamically favoured with respect to $\mathbf{8}$ 'ab.

On the other hand, azomethine ylide $\mathbf{8}_{\mathbf{s}}, \mathbf{a b}$ can be formed through rotation about $\mathrm{N}(d)-\mathrm{C}(c)$ bond in $\mathbf{8}_{\mathrm{w}} \mathbf{a b}$. Noteworthy, the computed activation barrier associated with this step strongly depends on the temperature considered. Our results show that the isomerization process is favoured at high temperatures (c.a. $6 \mathrm{kcal} \mathrm{mol}^{-1}$ lower than at room temperature) thus showing the importance of the entropic contribution to the Gibbs free activation barrier in this isomerization step. Moreover, formation of $\mathbf{8}_{\mathbf{s}}, \mathbf{a b}$ is a thermodynamically unfavoured process, since the hydrogen bond between the $\mathrm{NH}$ and carboxy moieties present in azomethine ylide $\mathbf{8} \mathbf{w} \mathbf{b}$ is stronger than the hydrogen bond between the arylidene $\mathrm{CH}$ and carboxy groups in $\mathbf{8}_{\mathbf{s}}, \mathbf{a b}$ (Scheme 7).
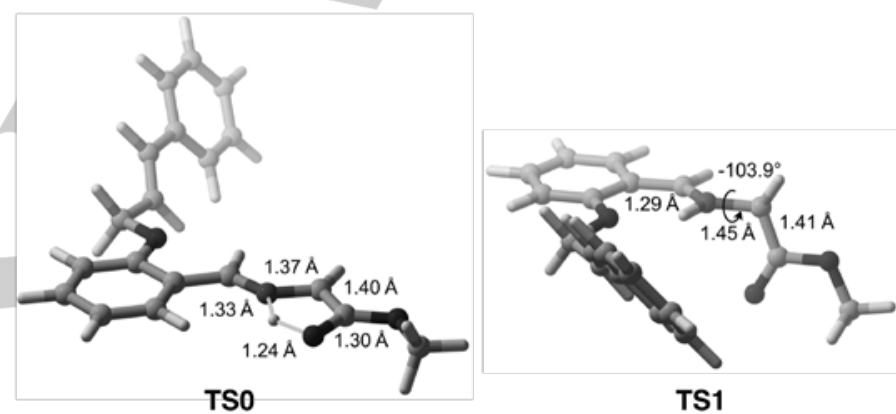

Figure 4. Main geometric features of transition structures associated with the formation of azomethine ylides $\mathbf{8}_{\mathrm{w}} \mathbf{a b}$ and $\mathbf{8}_{\mathbf{s}} \mathbf{a b}$ computed at the $B 3 L Y P(P C M) / 6-31 G *$ level of theory. Distances and angles are in $\AA$ and deg respectively.

Intramolecular [3+2] cycloadditions. Once we had calculated the reaction coordinates leading to azomethine ylides $\mathbf{8}_{\mathbf{s}}, \mathbf{a b}$ and $\mathbf{8}_{\mathbf{w}} \mathbf{a b}$, we analyzed the different intramolecular [3+2] pathways leading to tricyclic pyrrolidines $\mathbf{1 4 a b - 1 7 a b}$ shown in Table 1 . In those compounds, the double bond (namely dipolarophile moiety) is not attached to an electron-withdrawing group. Therefore, the expected two electron interactions required for the electronic circulation of pericyclic [3+2]-cycloadditions would be less favoured than those found for other dipolarophiles such as $\beta$-nitrostyrenes. ${ }^{[31 c]}$ The analysis of the frontier orbitals of azomethine ylides $\mathbf{8}_{\mathbf{s}}$, ab and $\mathbf{8}_{\mathrm{w}}$ ab shows that in the latter case the main two-electron interactions correspond to the HOMO1/LUMO and HOMO/LUMO+1 pairs (Figure 5A). According to this interaction scheme, the less energetic saddle point endo$\mathbf{T S}_{\mathrm{W}}$ should be the most synchronous one (Figure 6). In contrast, intramolecular cyclization of $\mathbf{8}_{\mathrm{s}}$, ab involves HOMO/LUMO and HOMO-1/LUMO+1 two-electron interactions (Figure 5B) thus leading to quite asynchronous transition structures.
Our calculations show that the initial enolization of $\mathbf{8 a b}$ is a highly endothermic process. Therefore, iminoenol 8'ab will be in low concentration in the reaction media. Once the transient enol 8'ab is formed, it can easily rearrange through a [1,5]-hydrogen 

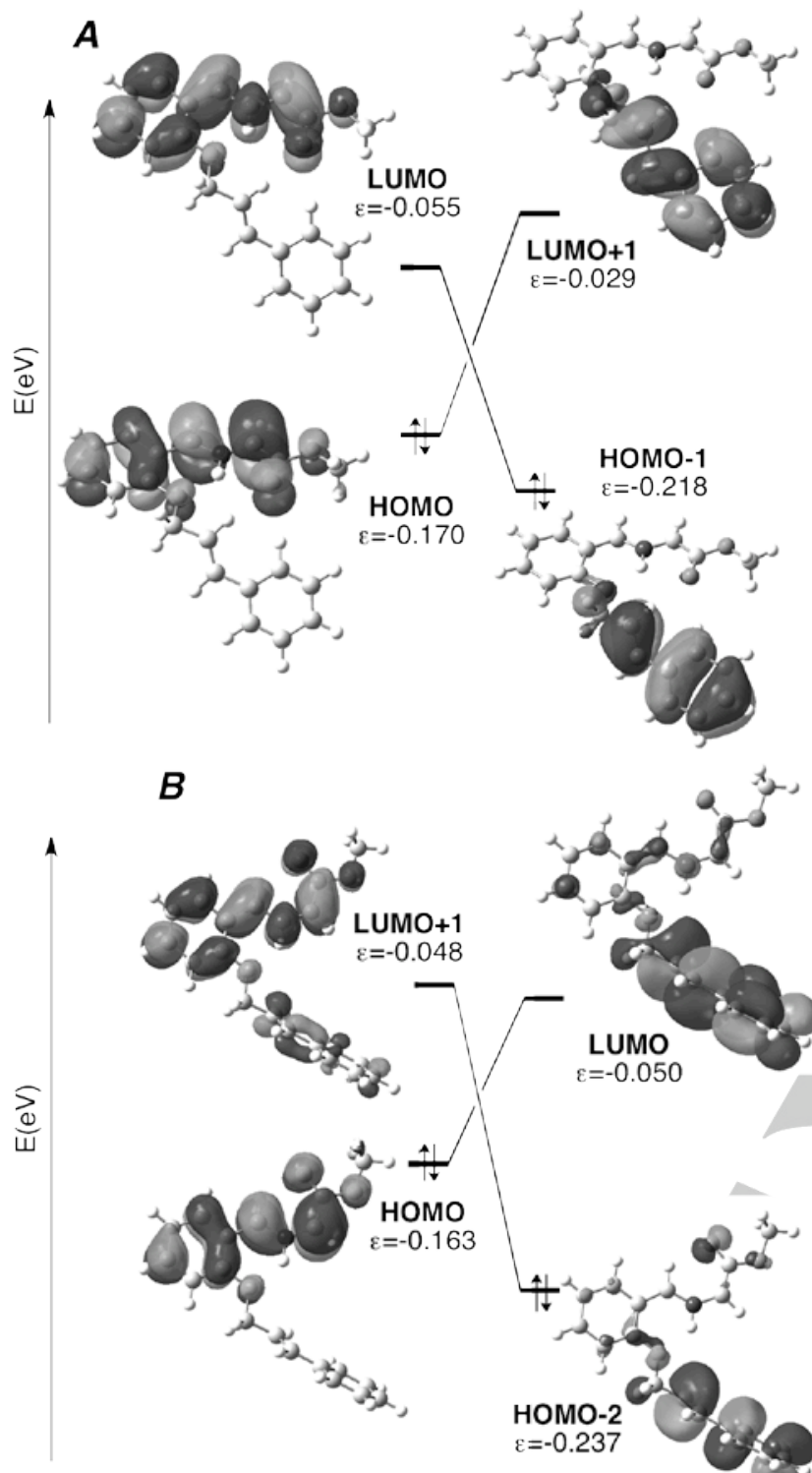

$B$

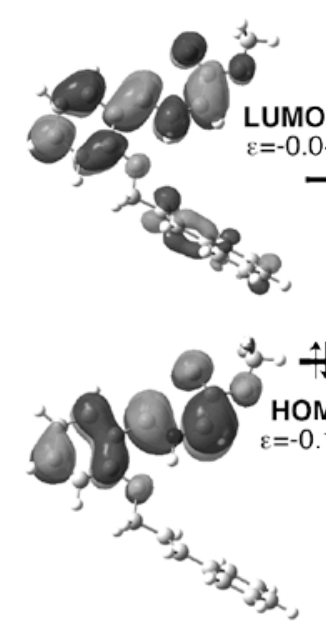

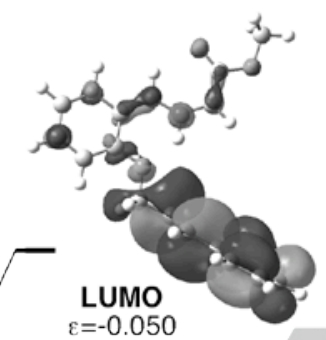<smiles>CC(=O)OC1NC2c3ccccc3OCC2[C@H]1c1ccccc1</smiles>

$15 \mathrm{ab}$

$-25.2(-21.1)$

[-25.7 (-18.0)]

$$
\mathrm{Ph} \uparrow \begin{gathered}
\text { endo-TS } \\
+13.5(+16.9) \\
{[+13.5(+19.5)]}
\end{gathered}
$$<smiles>C=CC1C=CC(=O)C(c2ccccc2OCC=CC)=[NH+]1</smiles>

$8_{\mathrm{S}} \mathbf{a b}$

$+11.9(+12.6)$

[+11.8 (+13.0)]

$\mid \begin{gathered}\text { exo-TS }_{\mathbf{S}^{\prime}} \\ +16.4(+19.3) \\ {[+16.4(+21.4)]}\end{gathered}$<smiles>CC(=O)C1NC2c3ccccc3OCC2C1c1ccccc1</smiles>

$17 \mathrm{ab}$<smiles>COC(=O)C1NC2c3ccccc3OCC2C1c1ccccc1</smiles>

$14 \mathrm{ab}$

$-26.8(-23.0)$

$[-27.2(-20.0)]$

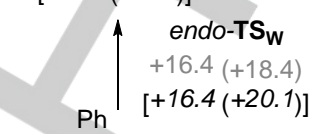<smiles>CC=CCO</smiles>

$\mathrm{O} \mathrm{H}^{\mathrm{H}}$

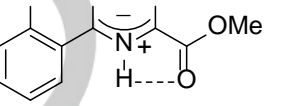
$8_{\mathrm{W}}$ ab $+8.3(+10.1)$ $[+8.2(+11.1)]$<smiles>COC(=O)C1NC2c3ccccc3OCC2C1c1ccccc1</smiles>

Scheme 8. Reaction profiles associated with the intramolecular [3+2] cyclization of azomethine ylides $\mathbf{8}_{\mathrm{w}} \mathbf{a b}$ and $\mathbf{8}_{\mathbf{s}}$, ab. Numbers below the compounds and arrows corresponds to the relative and activation energies respectively. The corresponding Gibbs energies are in parentheses. Values computed at $298.15 \mathrm{~K}$ are in grey. Values computed at $460.15 \mathrm{~K}$ are in italics, between brackets. All the results were computed at the M06-2X(PCM)/def2TZVPP//B3LYP(PCM)/6-31G* level of theory and are given in kcal $\mathrm{mol}^{-1}$.

According to our calculations, the endo-approaches present lower activation barriers than their exo-analogues. Moreover, azomethine ylide $\mathbf{8}_{\mathbf{S}}, \mathbf{a b}$ was found to be more reactive than its isomer $\mathbf{8}_{\mathrm{w}} \mathbf{a b}$, being endo-TS $\mathbf{S}_{\mathbf{S}}$, the saddle point with the lowest activation barrier. On the other hand, endo-cycloadducts 14ab and $\mathbf{1 5 a b}$ are more stable than exo-tricyclic pyrrolidines $16 \mathbf{a b}$ and $17 \mathrm{ab}$ so an increment of the temperature using harsh conditions favoured them. Therefore, formation of $14 a b$ and $\mathbf{1 5 b}$ are both thermodynamically and kinetically favoured. However, formation of $\mathbf{1 5}$ strongly depends on the previous isomerization step since all the activation barriers computed for the [3+2] cycloaddition steps were found to be quite similar in magnitude.

It is noteworthy that when higher temperatures were considered in the calculations the Gibbs activation barriers associated with the [3+2] cycloadditions increased substantially. This thermal effect can be ascribed to a lesser contribution of the entropic factor of this step compared to the previous isomerization process. 

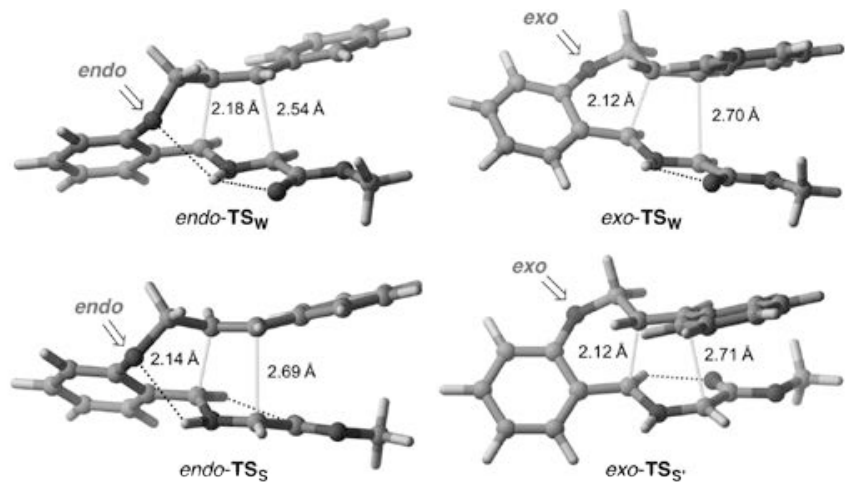

Figure 6. Main geometric features of transition structures associated with the intramolecular [3+2] cyclization of azomethine ylides $\mathbf{8}_{\mathbf{w}} \mathbf{a b}$ and $\mathbf{8}_{\mathbf{s}}, \mathbf{a b}$. See caption of Figure 4 for further details.

The analysis of the geometries of the computed transition structures showed that these intramolecular [3+2] cycloaddition reactions consist of concerted but quite asynchronous processes. Noteworthy, our calculations show that in these saddle points $C(e)-C(a)$ distances are shorter than the $C(c)-C(b)$ ones, a result contrary to that found for intermolecular [3+2]cycloadditions involving $\pi$-deficient alkenes. ${ }^{\left[{ }^{[d, 29 a, 31 c]}\right.}$ Moreover, the lower activation barrier computed for endo-cycloadditions can be ascribed to the presence of stabilizing electrostatic interactions between the $\mathrm{NH}$ and the alkoxy moieties, which cannot occur along the exo reaction paths (Figure 6). It is interesting to note that in the exo-saddle points the 3,4-dihydro$2 \mathrm{H}$-pyranyl ring of the chromane moiety being formed adopts a stable half-chair conformation, whereas in the case of the endo transition structures the $\mathrm{O} \cdots \mathrm{H}-\mathrm{N}$ interaction leads to an unexpected boat conformation for this six-membered ring.

Kinetic simulations. Our computed reaction paths involve complex profiles including enolization, pseudopericyclic, torsional and pericyclc elementary steps, many of them being significantly temperature-dependent. As a consequence, the stereochemical outcome for the whole process could not be deduced directly from the ensemble of activation energies. Therefore, we decided to perform kinetic simulations on the computed reaction profiles at the standard temperature of $298 \mathrm{~K}$ and at $460 \mathrm{~K}$, the temperature at which the experimental studies were carried out (vide supra).

Since the final steps leading to the [3+2] cycloadducts can be considered irreversible, the formation of 14ab-17ab can be described by equations (1)-(4):

$$
\begin{aligned}
& d / d t[\mathbf{1 4 a b}]=k_{N, M}\left[\mathbf{8}_{W} \boldsymbol{a} \boldsymbol{b}\right] \\
& d / d t[1 \mathbf{7 a b}]=k_{X, M}\left[\mathbf{8}_{W} \boldsymbol{a} \boldsymbol{b}\right] \\
& d / d t[\mathbf{1 5 a b}]=k_{N, S^{\prime}}\left[\mathbf{8}_{S^{\prime}} \boldsymbol{a} \boldsymbol{b}\right] \\
& d / d t[\mathbf{1 6 a b}]=k_{X, S^{\prime}}\left[\mathbf{8}_{S^{\prime}} \boldsymbol{a} \boldsymbol{b}\right]
\end{aligned}
$$

The concentration of azomethine ylides $\mathbf{8}_{\mathrm{w}} \mathbf{a b}$ and $\mathbf{8}_{\mathrm{s}}$, ab are described by equations (5) and (6):

$$
\begin{aligned}
& d / d t\left[\mathbf{8}_{W} \boldsymbol{a} \boldsymbol{b}\right]= \\
& k_{0}\left[\mathbf{8}^{\prime} \boldsymbol{a} \boldsymbol{b}\right]+k_{-1}\left[\mathbf{8}_{S^{\prime}} \boldsymbol{a} \boldsymbol{b}\right]-\left(k_{1}+k_{X, W}+k_{N, W}\right)\left[\mathbf{8}_{W} \boldsymbol{a} \boldsymbol{b}\right] \\
& d / d t\left[\mathbf{8}_{S^{\prime}} \boldsymbol{a} \boldsymbol{b}\right]=k_{1}\left[\mathbf{8}_{W} \boldsymbol{a} \boldsymbol{b}\right]-\left(k_{-1}+k_{X, S^{\prime}}+k_{N, S^{\prime}}\right)\left[\mathbf{8}_{S^{\prime}} \boldsymbol{a} \boldsymbol{b}\right]
\end{aligned}
$$

In eqs. (1)-(6) the meaning of the kinetic constants associated with the different elementary steps is that indicated in Figure 7. From the information contained in this Figure, it is clear that formation of cycloadducts 14ab-17ab only depends on the concentration of the azomethine ylides $\mathbf{8}_{\mathrm{w}} \mathbf{a b}$ and $\mathbf{8}_{\mathbf{s}}, \mathbf{a b}$. On the other hand, $\mathbf{8}_{\mathrm{w}} \mathbf{a b}$ can be generated from iminoenol $\mathbf{8}$ 'ab whereas $\mathbf{8}_{\mathbf{s}}$ ab only can be formed via isomerization of $\mathbf{8}_{\mathbf{w}} \mathbf{a b}$. This situation leads to a complex kinetic scheme in which kinetic constant $k_{1}$ acts as a threshold that controls the formation of cycloadducts $15 \mathrm{ab}$ and $16 \mathrm{ab}$

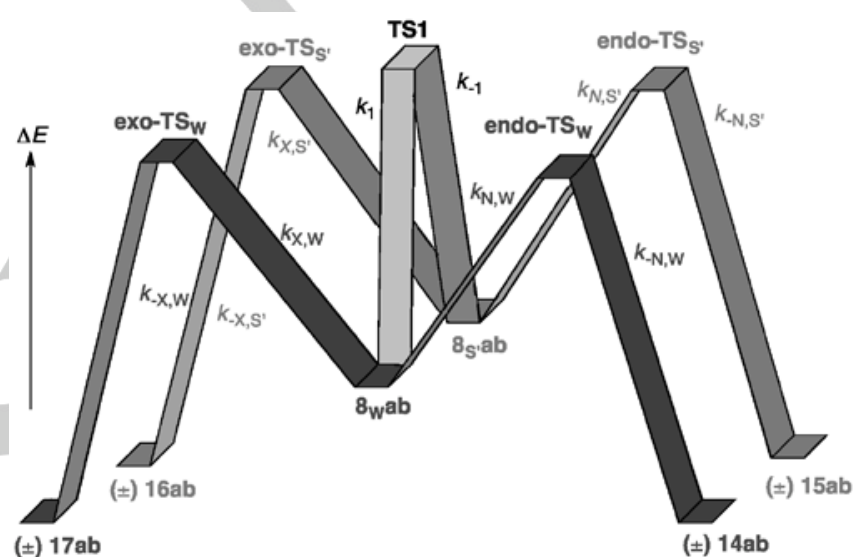

Figure 7. Qualitative diagram showing the different reaction paths and kinetic constants in the formation of cycloadducts 14ab-17ab.

We estimated the kinetic constants gathered in Figure 7 by means of the Eyring equation. ${ }^{[35]}$ The values for these constants can be found in the Supporting Information. Using these values, we performed Runge-Kutta numerical integration of the kinetic equations associated to the processes shown in Schemes 7 and 8. The outcome of these simulations is show in Figure 8.
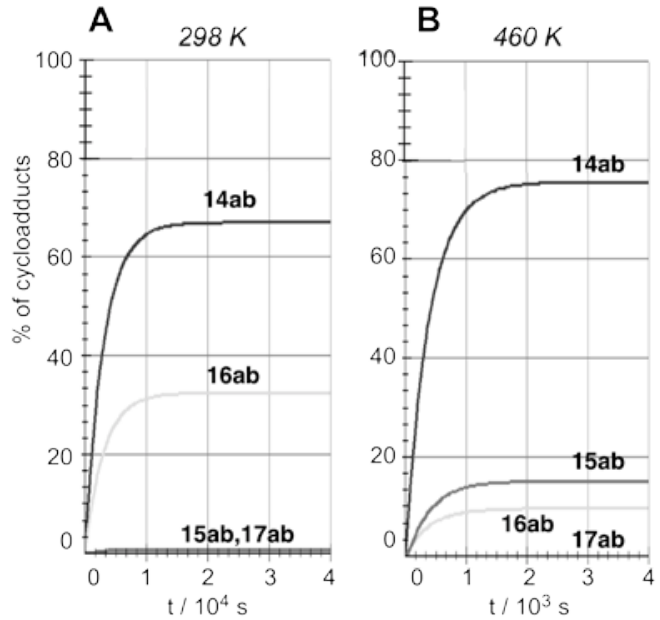
Figure 8. Simulated stereochemical outcome associated with the intramolecular $(3+2)$ cyclization of azomethine ylides $\mathbf{8}_{\mathrm{w}} \mathbf{a b}$ and 8 , ab at (A) $298 \mathrm{~K}$ and (B) $460 \mathrm{~K}$.

Our kinetic simulations show that the product ratio depends on the temperature considered in the calculations. At $298 \mathrm{~K}$, the cycloadducts that come from azomethine ylide $\mathbf{8}_{\mathbf{w}} \mathbf{a b}$ are the mayor products, thus showing no azomethine ylide isomerization occurs at this and lower temperatures. In this case, the simulated outcome shows a 14ab:16ab product ratio of 73:37. However, at high temperatures, the stereochemical outcome is qualitatively different. In this case, $\mathbf{1 4 a b}$ remains being the mayor product, but formation of $\mathbf{1 5 a b}$ is now possible because of the partial isomerization of 1,3-dipole $\mathbf{8}_{w} \mathbf{a b}$ to $\mathbf{8}_{\mathbf{s}}, \mathbf{a b}$. Thus, at $460 \mathrm{~K}$, our numerical simulations yield a 14ab:15ab:16ab ratio of $75: 17: 8$, which is in nice agreement with the experimentally found ratio of 65:24:11 (Table 1, entry 2).

\section{Conclusions}

Using this two component synthesis employing two different reaction conditions the preparation of chromene-[4,3- $b]$ pyrrolidines can be easily achieved. This is the first time that freshly generated imino ester was able to promote a intramolecular 1,3-dipolar cycloaddition from $6 \mathbf{a}$ with $\mathrm{R}^{1}=\mathrm{Ph}$. When $\mathrm{R}^{1}=$ Ar Method A (MW, 200W) gave compounds 14 as major stereoisomers in shorter reaction times, rather than Method B (PEG-400, $170^{\circ} \mathrm{C}$ ). Mixtures of 14, 15 and 16 were detected in variable proportions. Besides, when $\mathrm{R}^{1}=\mathrm{CO}_{2} \mathrm{Me}$ Methods $A$ and $B$ gave in most cases similar results furnishing molecules 14 as major stereoisomers together with cycloadducts 16. It was noticeable that in these examples compounds $\mathbf{1 5}$ were not identified in the crude reaction material. This strategy is the key to get adducts $\mathbf{1 6}$ after purification. Computational analysis of these $(3+2)$ intramolecular cycloadditions shows that formation of $\mathbf{W}$ and $\mathbf{S}$ ' 1,3-dipoles determines the stereochemical outcome of the reaction. The latter reactive species require higher temperatures to be formed from the corresponding imines. Intramolecular 1,3-dipolar reactions take place via relatively asynchronous transition structures, the endogeometries being the less energetic ones. The kinetic profile obtained from these computational studies are compatible with the preferential formation of mayor cycloadducts $14 \mathbf{a b}$ and $15 \mathbf{a b}$ at high temperatures, the former coming from the $\mathbf{w}$ 1,3-dipole and the latter form the corresponding $S^{\prime}$ analogue.

\section{Experimental Section}

General method for [3+2] cycloaddition to O-alkylatedsalicylaldehydes using microwave irradiation. To a solution of toluene $(0.7 \mathrm{~mL})$ in a Pyrex test tube, containing the corresponding 0 alkylated salicylaldehyde 6 (0.1 $\mathrm{mmol})$, the amino ester hydrochloride $(0.12 \mathrm{mmol})$, and triethylamine $(0.5 \mathrm{mmol})$, were added in this order. The mixture was submitted to microwave irradiation using $200 \mathrm{~W}$, at $185^{\circ} \mathrm{C}$ (see Table 1 for reaction times). For the 4-nitro-cinnamyl analogues $6 \mathrm{~b}$ the reactions are performed in dry toluene. After cooling, ethyl acetate was added and the mixture washed three times with brine, then $\mathrm{Na}_{2} \mathrm{SO}_{4}$ was added, filtered, and the organic phase was evaporated. The crude reaction mixture was purified by flash column chromatography on silica gel to provide the cycloadducts 14,15 and 16 as viscous oils. Yields, diastereomeric ratio and other details are described in Table 1, for characterization material see supporting information.

General method for [3+2] cycloaddition to O-alkylatedsalicylaldehydes in PEG-400. To a solution of PEG $(1.0 \mathrm{~mL})$ in a Pyrex test tube, containing the corresponding o-alkylated salicylaldehyde $6(0.1 \mathrm{mmol})$, the amino ester hydrochloride $(0.12$ $\mathrm{mmol})$, and triethylamine $(0.5 \mathrm{mmol})$, were added in this order. The mixture was heated at $170^{\circ} \mathrm{C}$ (see Table 1 for reaction times). After cooling, ethyl acetate was added and the mixture washed three times with brine, then $\mathrm{Na}_{2} \mathrm{SO}_{4}$ was added, filtered, and the organic phase was evaporated. The crude reaction mixture was purified by flash column chromatography on silica gel to provide the cycloadducts 14, 15 and 16 as viscous oils. Yields, diastereomeric ratio and other details are described in Table 1 , for characterization material see supporting information.

General method for the synthesis of sulfonamides 5 . To a solution of cycloadduct $14(0.1 \mathrm{mmol})$ in dry pyridine $(0.8 \mathrm{~mL})$ tosyl chloride $(0.25 \mathrm{mmol})$ was added. The reaction was heated at $80^{\circ} \mathrm{C}$ for $15 \mathrm{~h}$. Then, the mixture was cooled to room temperature, the pyridine was removed under vacuo and warm methanol was added until total crude's solubilization. Water was added and the precipitation of sulfonamide occurred. The mixture was centrifuged and the aqueous layers separated giving pure sulfonamide $\mathbf{5}$ as single diastereoisomer. Yield, temperature and other physical data are described in Scheme 3 and in the supporting information.

Computational Methods. Conformational analyses were carried out with the $\mathrm{MM} 3$ force field ${ }^{36}$ in $\mathrm{CHCl}_{3}$ as implemented in MacroModel. ${ }^{37}$ Conformational searches were performed by means of Monte Carlo simulations. ${ }^{38}$ All the computational mechanistic studies were carried out by means of either Gaussian $09^{[39]}$ suite of programs. Density Functional Theory ${ }^{[40]}$ (DFT) calculations were performed using the B3LYP ${ }^{[41]}$ and $M 06-2 X^{[42]}$ functionals. This latter highly parameterized method is well suited for the treatment of nonbonding interactions and dispersion forces, which can be relevant in densely substituted interaction systems. ${ }^{[43]}$ The $6-31 G^{*}$ and def2-TZVPP basis sets were used. All the stationary points were characterized by harmonic analysis. ${ }^{[4]}$ Reactants, intermediates and products showed positive definite Hessians. Transition structures (TSs) showed one and only one imaginary frequency associated with nuclear motion along the chemical transformation under study. Free energies at 298.15 and $460.15 \mathrm{~K}$ were calculated by including the corresponding thermal corrections to Gibbs free energies (TCGE). Figures including optimized structures were made with Maestro ${ }^{45}$ and CYL-view programs. ${ }^{46}$ Orbital interaction diagrams were prepared using Gauss-view interface. ${ }^{47}$

\section{Acknowledgements}

Financial support was provided by the UFRJ, FAPERJ and CAPES in Brazil, Spanish Ministerio de Ciencia e Innovación (MICINN) (projects CTQ2010-20387, and Consolider Ingenio 2010, CSD200700006), the Spanish Ministerio de Economía y Competitividad (MINECO) (projects CTQ2013-43446-P, CTQ2014-51912-REDC, and CTQ2013-45415-P), FEDER, the Generalitat Valenciana (PROMETEO 2009/039 and PROMETEOII/2014/017), the Basque Government (GV/EJ, grant IT-324-07), and the Universities of Alicante and of the Basque Country (UPV/EHU, UFI11/22 QOSYC).The authors thank the SGI/IZO-SGIker UPV/EHU and the DIPC for generous allocation of computational and analytical resources. Technical and human support provided by SGIker (UPV/EHU, MINECO, GV/EJ, ESF) is gratefully acknowledged. 
Keywords:[3+2] Cycloadditions • Intramolecular reactions •

states

Azomethine ylides $\bullet$ Kinetics $\bullet$ Reaction mechanisms $\bullet$ Transition
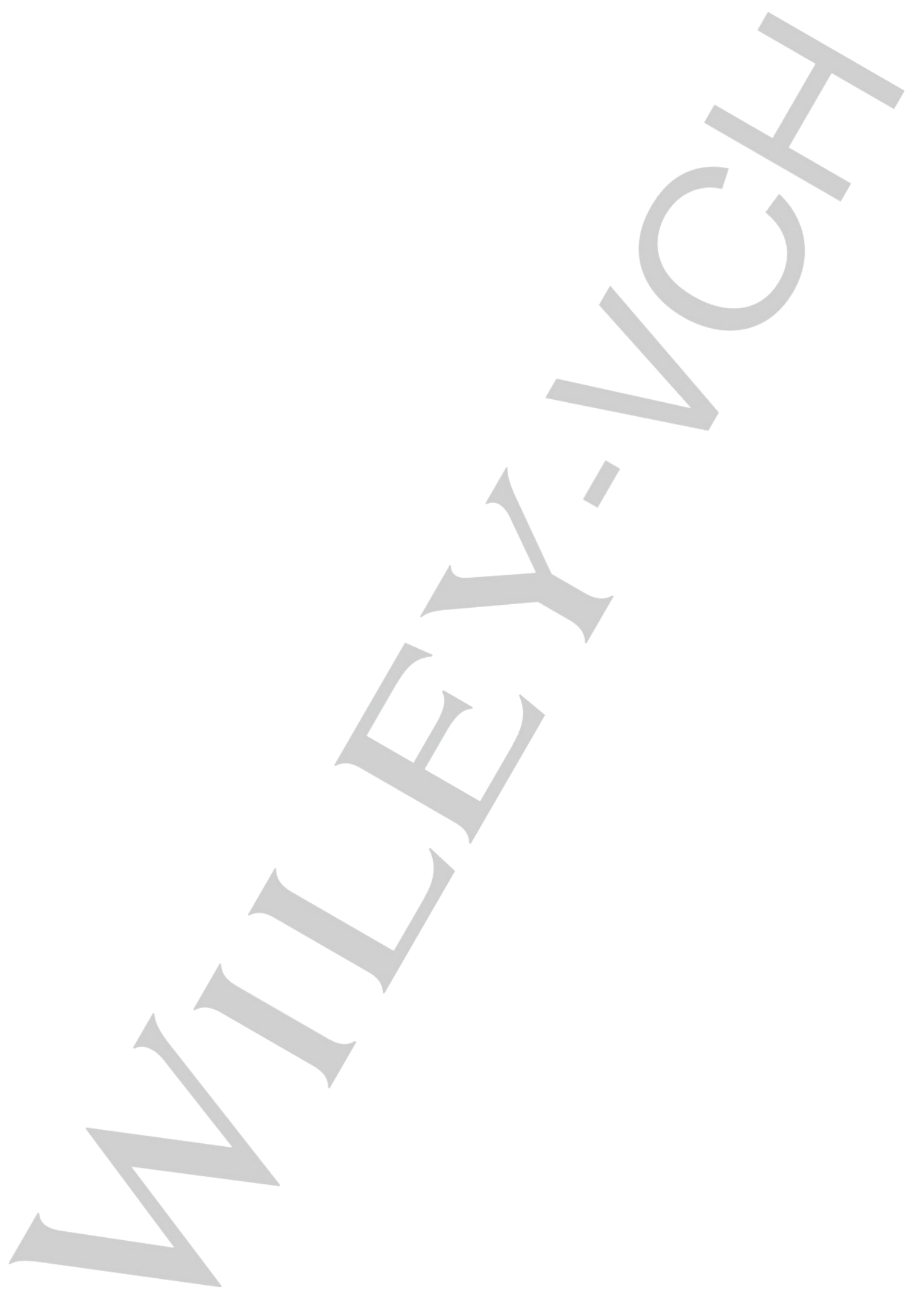
Layout 1:

\section{FULL PAPER}

Text for Table of Contents

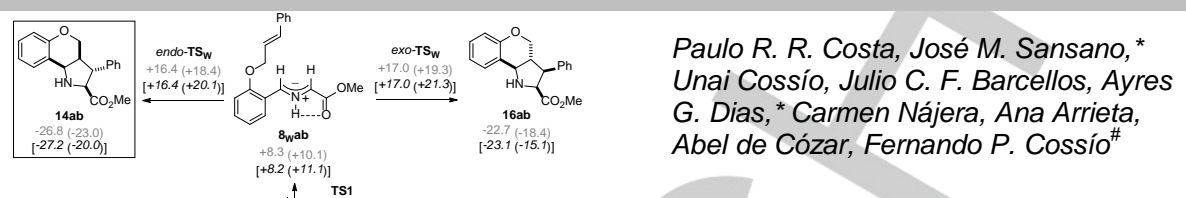

Page No. - Page No.

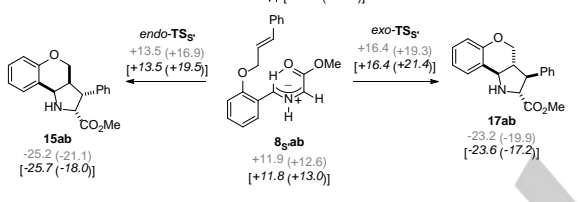

Title: Synthesis of Chromen[4,3b]pyrrolidines by Intramolecular 1,3Dipolar Cycloadditions of Azomethine Ylides: Experimental and Computational Assessment of the Origins of Stereocontrol

\section{References}

[1] This skeleton was firstly found in naturally occurring martinelline or martinellic acid alkaloid derivatives, which are bradikinin receptor antagonists. C. J. Lovely, V. Badarinarayana, Curr. Org. Chem. 2008, 12, 1431-1453.

[2] This arrangement is present in Sceletium alkaloids A4. P. N. Confalone, E. M. Huie, J. Am. Chem. Soc. 1984, 106, 7175-7178.

[3] C. E. Augelli-Szafran, C. J. Blankley, J. C. Jaen , D. W. Moreland, C. B. Nelson, J. R. Penvose-Yi , R. D. Schwarz , A. J. Thomas, J. Med. Chem. 1999, 42, 356-363.

[4] N. Arumugam, R. Raghunathan, A. I. Almansour, U. Karama, Bioorg. Med. Chem. Lett. 2012, 42, $1375-1379$.

[5] N. J. Parmar, B. R. Pansuriya, H. A. Barad, R. Kant, V. K. Gupta, Bioorg. Med. Chem. Lett. 2012, 42, 4075-4079.

[6] C. D. Buarque, G. C. G. Militão, D. J. B. Lima, L. V. Costa-Lotufo, C. Pessoa, M. Odorico de Moraes, E. Ferreira Cunha-Junior, E. C. Torres-Santos, C. D. Netto, P. R. R. Costa, Bioorg. Med. Chem. 2011, 19, 6885-6891.

[7] During the preparation of the manuscript, compounds 5 resulted to be promising inhibitors of TNF- $\alpha$ expression in macrophages (unpublished results).

[8] a) Synthetic Applications of 1,3-Dipolar Cycloaddition Chemistry Towards Heterocycles and Natural Products, A. Padwa, W. H. Pearson, Eds. John Wiley\&Sons, New Jersey, 2003; b) C. Nájera, J. M. Sansano, Curr. Org. Chem. 2003, 7, 1105-1150; c) W. Eberbach, Sci. Synth. 2004, chp. 11, 441-498; d) I. Coldham, R. Hufton, Chem. Rev. 2005, 105, 2765-2810; e) V. Nair, T. D. Suja, Tetrahedron 2007, 63, 12247-12275; f) A. Padwa,; S. K. Bur, Tetrahedron 2007, 63, 5341-5378; g) S. Kanemasa, Heterocycles 2010 , 82, 87-200; h) W. Zhang, Chem. Lett. 2013, 42, 676-681.

[9] a) R. Huisgen, W. Scheer, H. Mader, Angew. Chem., Int. Ed. Engl. 1969, 8, 602-604; b) R. Huisgen, W. Scheer, H. Mader, E. Brunn, Angew. Chem., Int. Ed. Engl. 1969, 8, 604-606.; c) H. Hermann, R. Huisgen, H. Mader, J. Am. Chem. Soc. 1971, 93, 1779-1781; d) R. Huisgen, H. Mader, J. Am. Chem. Soc. 1971, 93, 1777-1779.

[10] a) C. Nájera, J. M. Sansano, Angew. Chem. Int. Ed. 2005, 44, 6272-6276; b) G. Pandey, P. Banerjee, S. R. Gadre, Chem. Rev. 2006, 106, 4484-4517; c) H. Pellissier, Tetrahedron 2007, 63, 3235-3285; d) L. M. Stanley, M. P. Sibi, Chem. Rev. 2008, 108, 2887-2902; e) C. Nájera, J. M. Sansano, Monatsh. Chem. 2011, 142, 659-680; f) J. Adrio, J. C. Carretero, Chem. Commun. 2011, 47, 6784-6794; g) A. L. Cardoso, T. M. V. D. Pinho e Melo, Eur. J. Org. Chem. 2012, 6479-6501; h) J. Adrio, J. C. Carretero, Chem. Commun. 2014, 50, 12434-12446.

[11] a) R. Narayan, M. Potowski, Z.-J. Jia, A. P. Antonchick, Acc. Chem. Res. 2014, 47, 1296-1310; b) C. Nájera, J. M. Sansano, Org. Biomol. Chem. 2009, 7, 4567-4581; c) E. San Sebastián, T. Zimmerman, A. Zubía,Y. Vara, E. Martín, F. Sirockin, A. Dejaegere, R. H. Stote, X. López, D. Pantoja-Uceda, M. Valcárcel, L. Mendoza, F. Vidal-Vanaclocha, F. P. Cossío, F. J. Blanco, J. Med. Chem. 2013, 56, 735-747; d) A. Zubía, L. Mendoza, S. Vivanco, E. Aldaba, T. Carrascal, B. Lecea, A. Arrieta, T. Zimmerman, F. VidalVanaclocha, F. Cossío, Angew. Chem. Int. Ed. 2005, 44, 2903-2907; e) A. Zubía, S. Ropero, D. Otaegui, E. Ballestar, M. F. Fraga, M. Boix-Cornet, M. Berdasco, A. Martínez, L. Coll-Mulet, J. Gil, F. P. Cossío, M. Esteller, Oncogene 2009, $28,1477-1484$.

[12] a) A. Mateo-Alonso, C. Sooambar, M. Prato, Org. Biomol. Chem. 2006, 4, 1629-1637; b) M. Quintana, M. Grzelczak, M. Prato, Phys. Status Solidi B 2010, 247, 2645-2648; c) M. Quintana, E. Vázquez, M. Prato, Acc. Chem. Res. 2013, 46, 138-148; d) E. E. Maroto, A. de Cózar, S. Filippone, A. Martín-Domenech, M. Suárez, F. P. Cossío, N. Martín, Angew. Chem. Int. Ed. 2011, 50, 60606064; e) E. E. Maroto, S. Filippone, M. Suárez, R. Martínez-Álvarez, A. de Cózar, F. P. Cossío, N. Martín, J. Am. Chem. Soc. 2014, 136, 705-712.

[13] For the application of this methodology in very complex skeletons, see for example: a) R. Grigg, L. M. Duffy, M. J. Dorrity, J. F. Malone, S. Rajviroongit, M. Thornton-Pett, Tetrahedron 1990, 46, 2213-2230; b) L. E. Overman, J. E. Tellew, J. Org. Chem. 1996, $61,8338-8340$. 
[14] Other methods for the generation of azomethine ylides have been employed: a) S. Kanemasa, K. Sakamoto, O. Tsuje, Bull. Chem. Soc. Jpn. 1989, 62, 1960-1968; b) B. S. Orlek, P. G. Sammes, D. J. Weller, J. Chem. Soc., Chem. Commun.1993, 1412-1413.

[15] Y. D. Gong, S. Najdi, M. M. Olmstead, M. J. Kurth, J. Org. Chem. 1998, 63, 3081-3086.

[16] Compounds 11 were also prepared using a thermal arrangement sequence, A. F. Khlebnikov, M. S. Novikov, R. R. Kostikov, J. Kopf, Russ. J. Org. Chem. 2005, 41, 1367-1374.

[17] Enantioselective [3+2] cyclization from 8 was also achieved when a chiral PHOX ligand or a chiral phosphoric acid were used: a) R. Stohler, F. Wahl, A. Pfaltz, Synthesis 2005, 1431-1436; b) N. Li, J. Song, Tu, X.-F.; Liu, B.; Chen, X.-H.; Gong, L.-Z. Chem. Commun. 2010, 2016-2019.

[18] a) R. Grigg, M. W. Jordan, J. F. Malone, Tetrahedron Lett. 1979, 3877-3878; b) P. A. Armstrong, R. Grigg, M. W. Jordan, J. F. Malone, Tetrahedron 1985, 41, 3547-3558; c) D. A. Barr, R. Grigg, M. Q. N. Gunaratne, J. Kemp, P. McMeekin, V. Sridharan, Tetrahedron 1988, 44, 557-570.

[19] N. Arumugan, R. Raghunathan, A. I. Almansour, U. Karama, Bioorg. Med. Chem. Lett. 2012, 22, 1375-1379.

[20] Compound $11\left(\mathrm{R}^{1}, \mathrm{R}^{3}, \mathrm{R}^{5}=\mathrm{H}, \mathrm{R}^{2}=\mathrm{CO}^{2} \mathrm{Me}, \mathrm{R}^{4}=\mathrm{Et}, \mathrm{X}=\mathrm{O}\right)$, was prepared using imine route in 38\% yield and 5:1 dr from the corresponding starter $\mathbf{8}$ [see, ref. 18b, 18c].

[21] Iminium salts $\mathbf{1 0}$ were allowed to react under thermal conditions in a solvent-free process to yield products 11. N. J. Parmar, B. R. Pansuriya, H. A. Barad, R. Kant, V. K. Gupta, Bioorg. Med. Chem. Lett. 2012, 22, 4075-4079.

[22] G. Bashiardes, I. Safir, A. S. Mohamed, F. Barbot, J. Laduranty, Org. Lett. 2003, 5, 4915-4918.

[23] J. Pospisil, M. Potacek, Tetrahedron 2007, 63, 337-346.

[24] The synthesis of hexahydrobenzofuro[3,2-b]pyrroles employing a similar strategy has been also reported. I. Kim, H.-K. Na, K. R. Kim, S. G. Kim, G. H. Lee, Synlett 2008, 2069-2071.

[25] Ketoimino esters underwent complete diastereoselective intramolecular 1,3-DC: P. Pandit, N. Chatterjee, D. K. Maiti, Chem. Commun. 2011, 47, 1285-1287.

[26] The nitrogenated version of this intramolecular cycloaddition $(X=N P G)$ is also known: a) M. Neuschl, D. Bogdal, M. Potacek, Molecules 2007, 12, 49-59; b) I. Kim, H.-K. Na, K. R. Kim, S. G. Kim, G. H. Lee, Synlett 2008, 2069-2071; c) P. Pandit, N. Chatterjee, D. K. Maiti, Chem. Commun. 2011, 47, 1285-1287

[27] CCDC-1056848 contains the supplementary crystallographic data for this paper. These data can be obtained free of charge from The Cambridge Crystallographic Data Centre via www.ccdc.cam.ac.uk/data_request/cif.

[28] CCDC-1056849 contains the supplementary crystallographic data for this paper. These data can be obtained free of charge from The Cambridge Crystallographic Data Centre via www.ccdc.cam.ac.uk/data request/cif.

[29] a) A. De Cózar, F. P. Cossío, Chem. Phys. Phys. Chem. 2011, 13, 10858-10868; b) A. Arrieta, M. C. de la Torre, A. de Cózar, M. A Sierra, F. P. Cossío, Synlett 2013, 24, 535-549.

[30] a) K. N. Houk, J. González, Y. Li, Acc. Chem. Res. 1995, 28, 81-90; b) R. Huisgen, In 1,3-Dipolar Cycloaddition Chemistry; A. Padwa, Ed.; Wiley: New York, 1984; Vol 1, pp 1-176; c) K. N. Houk, J. Sims, C. R. Watts, L. J. Luskus, J. Am. Chem. Soc. 1973, 95, 7301-7315; d) K. N. Houk, Acc. Chem. Res. 1975, 8, 361-369; e) D. H. Ess, K. N. Houk, J. Am. Chem. Soc. 2008, 130, 1018710198; f) B. Braida, C. Walter, B. Engels, P. C. Hiberty, J. Am. Chem. Soc. 2010, 132, 7631-7637; g) L. Xu, C. E. Doubleday, K. N. Houk, J. Am. Chem. Soc. 2010, 132, 3029-3037.

[31] a) S. Vivanco, B. Lecea, A. Arrieta, P. Prieto, I. Morao, A. Linden, F. P. Cossío, J. Am. Chem. Soc. 2000, 122, 6078-6092; b) M. Ayerbe, A. Arrieta, F. P. Cossío, A. Linden, J. Org. Chem. 1998, 63, 1795-1805; c) A. Arrieta, D. Otaegui, A. Zubía, F. P. Cossío, A. Díaz-Ortiz, A. de la Hoz, M. A. Herrero, P. Prieto, C. Foces-Foces, J. L. Pizarro, M. I. Arriortua, J. Org. Chem. 2007, 72, 4313-4322.

[32] a) I. Coldham, R. Hufton, Chem. Rev.2005, 105, 2765-2809; b) V. Nair, T. D. Suja, Tetrahedron 2007, 63, 12247-12275.

[33] a) W. Eberbach, H. Fritz, I. Heinze, P. Von Laer, P. Link, Tetrahedron Lett. 1986, 27, 4003-4006; b) A. Padwa, H. Ku, J. Org. Chem. 1979, 44, 255-261.

[34] C. Zhou, D. M. Birney, J. Am. Chem. Soc. 2002, 124, 5231-5241.

[35] F. P. Cossío, Calculation of Kinetic data Using Computational Methods. In Rate Constant Calculation for Thermal Reactions; H. Da Costa, M. Fan. Eds.;Willey:Hoboken, NJ, 2012; pp 33-65.

[36] a) N. L. Allinger, Y. H. Yuh, J.-H. Lii, J. Am. Chem. Soc. 1989, 111, 8551-8565; b) J.-H. Lii, N. L. Allinger, J. Comput. Chem. 1991, 12, 186-199; c) N. L. Allinger, Molecular Structure-Understanding Steric and Electronic Effects from Molecular Mechanics; Wiley: Hoboken New York, 2010.

[37] MacroModel, version 10.0, Schrödinger LLC, New York, 2013.

[38] a) G. Chang, W. C. Guida, W. C. Still, J. Am. Chem. Soc.1989, 111, 4379-4386; b) J. M. Goodman, W. C. Still, J. Comput. Chem. 1991, 12, 1110-1117.

[39] Gaussian-09, Revision A.02, M. J. Frisch et al., Gaussian Inc., Wallingford CT, 2009 (full reference in Supporting Information).

[40] R. G. Parr, W. Yang, Density-Functional Theory of Atoms and Molecules, Oxford, New York, 1989.

[41] A. D. Becke, J. Chem. Phys. 1993, 98, 5648-5650.

[42] Y. Zhao, D. G.Truhlar, Theor. Chem. Acc. 2007, 120, 215-241.

[43] a) Y. Zhao, D. G. Truhlar, Acc. Chem. Res. 2008, 41, 157-167; b) J.-L. Chen, J.-T. Hong, K.-J. Wu, W.-P. Hu, Chem. Phys. Lett. 2009, 468, 307-312.

[44] R. Cammi, B. Mennucci, J. Tomasi, J. Phys. Chem. A 2000, 104, 5631-5637.

[45] Maestro, version 9.2, Schrödinger LLC, New York, 2013.

[46] C. Y. Legaut, CYL view v1.0.374 BETA, 2007-2010.

[47] Gauss View, version 5.0, Roy Dennington, Todd Keith, and John Millam, Semichem Inc., Shawnee Mission, KS, 2009. 